\title{
CIDADANIA E DEMOCRACIA: A PARTICIPAÇÃO DA SOCIEDADE CIVIL NO PROCESSO DECISÓRIO DA POLÍTICA URBANA NO BRASIL
}

\author{
CITIZENSHIP AND DEMOCRACY: THE PARTICIPATION OF CIVIL SOCIETY IN THE \\ DECISION-MAKING PROCESS OF URBAN POLICY IN BRAZIL
}

Wesley Pinto CARNEIRO1 ${ }^{1}$, Jairo de Carvalho GUIMARÃES²

Artigo recebido em 16/02/2021, aceito em 22/06/2021, publicado em 13/07/2021.

\begin{abstract}
RESUMO
Palavras-chave:

Participação;

Cidadania;

Sociedade

Politica Urbana.

O estudo tem como objetivo discutir a participação da sociedade civil no processo decisório da Política Urbana, a partir de reflexões sobre a conquista da cidadania, a democracia participativa e a inserção popular na tomada de decisões na gestão do espaço urbano. Este trabalho apresenta as discussões a respeito do conceito de cidadania, bem como uma análise da participação da sociedade nas democracias representativas e participativas. 0 desenvolvimento do trabalho está estruturado da seguinte forma: inicialmente, discute-se os conceitos e noções de cidadania, em seguida apresenta-se as contribuições teóricas que avançam na discussão da participação no campo da gestão pública e, por fim, apresentam-se as profundas mudanças na Política Urbana no Brasil que ocorreram nas últimas décadas do século XX, decorrentes das reivindicações dos movimentos sociais no fortalecimento da participação popular na Política Urbana. Utilizou-se como procedimentos metodológicos a pesquisa bibliográfica, por meio de obras de autores clássicos e contemporâneos referentes à cidadania, à democracia deliberativa, à sociedade civil, à Política Urbana e à gestão urbana. Como resultados pode-se constatar a inexpressiva participação da sociedade civil no âmbito da gestão do espaço urbano e na formulação de Políticas Públicas voltadas para as cidades.
\end{abstract}

Keywords:
Participation;
Citizenship;
Civil society; Urban
Policy.

\section{ABSTRACT}

The study aims to discuss the participation of civil society in the decision-making process of Urban Policy, based on reflections on the achievement of citizenship, participatory democracy and popular inclusion in decision-making in the management of urban space. This work presents discussions about the concept of citizenship, as well as an analysis of society's participation in representative and participatory democracies. The development of the work is structured as follows: initially, the concepts and notions of citizenship are discussed, then the theoretical contributions that advance the discussion of participation in the field of public management are presented and, finally, the profound changes in Urban Policy in Brazil that occurred in the last decades of the 20th century, arising from the demands of social

\footnotetext{
${ }^{1}$ Doutorando em Políticas Públicas pela Universidade Federal do Piauí-UFPI e Mestre em Geografia pela Universidade Federal do Piauí. Atualmente é Professor Assistente Il da Coordenação e subcoordenador do Curso de Geografia do Campus Petrônio Portela da Universidade Federal do Piauí-UFPI em Teresina-PI .

${ }^{2}$ Doutor em Educação pela Universidade Federal do Rio de Janeiro e professor permanente do Programa de Pós-Graduação em Políticas Públicas (PPGPP) vinculado ao CCHL - Centro de Ciências Humanas e Letras (Teresina-PI).
} 
movements to strengthen popular participation in Urban Policy. The bibliographical research was used as methodological procedures, through works of classic and contemporary authors referring to citizenship, deliberative democracy, civil society, Urban Policy and urban management. As a result, it can be seen the inexpressive participation of civil society in the management of urban space and in the formulation of Public Policies aimed at cities.

\section{INTRODUÇÃO}

Os direitos do cidadão são conquistados, paulatinamente, ao longo do tempo. Portanto, podem ser considerados históricos e resultam das relações e dos conflitos sociais em determinados momentos no processo evolutivo da história da sociedade. Com efeito, ao analisar o processo de formação do conceito de cidadania, nota-se que este é pautado pelas dicotomias, avanços e retrocessos e, sobretudo, tendo como linha norteadora a luta pelos interesses dos grupos sociais que foram construindo, ao longo do tempo, a cidadania brasileira. $\mathrm{O}$ fato é que o fortalecimento da democracia perpassa pela consolidação da cidadania ativa dos atores sociais, cujos direitos sociais são assegurados a partir da efetiva participação do indivíduo nas decisões relacionadas às Políticas Públicas, qualquer que seja a dimensão envolvida - Saúde, Educação, Infraestrutura, Urbanismo, Segurança, etc.

A título de exemplo, na França do século XVIII, estavam sendo discutidos os direitos à vida, à liberdade, à igualdade e à participação do ator social na vida pública, e no Brasil, nesse mesmo período, a escravidão estava demasiadamente longe de conseguir tais direitos, os quais eram assegurados somente aos que detinham o poder da propriedade. Sobre as perspectivas que se reportam à igualdade e à liberdade, Tocqueville (2019, p. 587) faz a seguinte colocação: "Os homens serão perfeitamente livres porque serão todos inteiramente iguais, e serão perfeitamente iguais porque serão inteiramente livres. É em direção a esse ideal que tendem os povos democráticos", arrematando que "a igualdade se estabelece na sociedade civil, mas não pode reinar no mundo político".

No Brasil, vieram primeiro as Leis que contemplavam os direitos sociais. Muito tempo depois surgiu a preocupação com os direitos políticos. Assim, a concepção de cidadania foi bastante prejudicada e isto tem estreita conexão com o processo participativo do tecido societário no processo de consolidação da ordem democrática. Para Santos (2013, p 227), constata-se a ideia de que a "[...] opacidade entre representante e representado", adicionada do distanciamento e da diferenciação entre estes, reforça a concepção de que, na democracia, a cidadania está restrita a aspectos meramente políticos, produzindo uma aderência quase nula, no que se refere aos direitos e prerrogativas sociais do sujeito livre e comum. Em reforço, Silveira (2017, p. 491) assenta que, sob esta condição, observa-se a "[...] incompletude da cidadania [...]", provocando a supressão de direitos sociais, os quais, historicamente, são conquistados por meio das lutas e dos 
movimentos sociais. $\mathrm{O}$ fato é que em um Estado Democrático de Direito, a formação da cidadania precisa estar fundada na efetiva participação da sociedade, com direito à comunicação política e ao controle social (Morbini \& Melo, 2020). Diante dessa constatação, lança-se o seguinte problema: para fortalecer a cidadania, de que forma os arranjos sociais podem desenvolver mecanismos de participação ativa na implementação da Política Urbana no Brasil, tendo como realidade uma democracia excludente?

No entanto, nas últimas décadas do século $X X$ ocorreu um certo avanço no que diz respeito à discussão sobre a participação dos atores sociais na gestão pública, tendo como propósito primeiro a valorização da democracia participativa. As mudanças no cenário político brasileiro, principalmente a partir da década de 1980, provocaram uma certa insatisfação popular diante de um quadro de desigualdades sociais nas cidades brasileiras. Dessa forma, os movimentos pela reforma urbana reivindicaram a inserção de artigos na Constituição Federal de 1988 que tratassem da Política Urbana, o que influenciou consideravelmente o fortalecimento da participação popular na gestão do espaço urbano.

Diante do exposto, o presente trabalho tem como objetivo discutir o processo de participação popular na Política Urbana brasileira, a partir da discussão das noções de cidadania e das reflexões sobre a democracia participativa, e a inserção popular na tomada de decisões da gestão do espaço urbano.

O desenvolvimento do trabalho está estruturado da seguinte forma: inicialmente, discute-se os conceitos e noções de cidadania, a partir das reflexões teóricas dos trabalhos de Marshall (1967); Carvalho (2008); Bobbio (1992) e Arendt (2000). Em seguida, apresentam-se as contribuições teóricas de Nogueira (2004) e os autores Faleiros (2010), Dagnino (2004), Avritzer (2000), Faria (2000) e Habermas (1984) que avançam na discussão da participação no campo da gestão pública e por fim, Villaça (1999), Secchi, Coelho \& Pires (2019), Silva (2003), Soares \& Gondim (1998) discutem a expansão da participação popular no processo decisório da Política Urbana brasileira com a aprovação do Estatuto da Cidade, com o estudo de Santos Junior \& Montandon (2011), analisando a implementação dos Planos Diretores Participativos.

\section{CIDADANIA E A CONQUISTA DE DIREITOS SOCIAIS}

As discussões acerca do conceito de cidadania remontam há bastante tempo na história da humanidade e sofreram inúmeras transformações com as revoluções burguesas e 0 ideal de liberdade, igualdade e fraternidade. O autor T. H. Marshall (1967), em sua obra intitulada "Cidadania, classe social e status" analisa o desenvolvimento da cidadania na Inglaterra enquanto conformada pelos direitos civis, políticos e sociais, e o impacto desta nas classes sociais. Marshall (1967) produz seu texto tendo como parâmetro as ideias de Alfred Marshall, cuja análise o faz concluir que a cidadania é uma espécie de igualdade humana básica associada com o conceito de participação integral na comunidade. 
Marshall (1967) entende o conceito de cidadania como um modo de viver que brota no interior de cada indivíduo e não como algo imposto pela sociedade. Assim, apenas um direito era considerado incontestável, o direito das crianças serem educadas. A Educação é considerada formadora da cidadania, e ao mesmo tempo, o mais essencial de todos os direitos do cidadão. No entanto, Marshall (1967) afirma que Alfred Marshall não imaginava que haveria o desenvolvimento de vários direitos e que isso fortaleceria a igualdade humana básica de participação. Assim, ele relata que "desenvolveu-se muito além do que Marshall previra ou teria desejado" (Marshall, 1967, p. 62).

Nesse sentido, a despeito do conceito de cidadania, Marshall (1967, p. 76) afirma que "é um status concedido aqueles que são membros integrais de uma comunidade. Todos aqueles que possuem status são iguais com respeito aos direitos e obrigações pertinentes ao status". 0 autor compreende que o desenvolvimento da cidadania coincide com o desenvolvimento do capitalismo. Ressalta que a cidadania, nas suas formas iniciais, constitui um princípio de igualdade e durante aquele período era uma instituição em desenvolvimento. Desse modo, na teoria, os homens eram livres, capazes de gozar de todos os direitos. Entretanto, esses direitos não entravam em conflito com as desigualdades da sociedade capitalista: era ao contrário, fundamentais para a manutenção daquela determinada forma de desigualdade.

Para Marshall (1967), formulador da teoria da cidadania, existe distinção entre as várias dimensões da cidadania. A cidadania política - a qual corresponde ao reconhecimento do direito de eleger representantes para a governabilidade e a legislatura; a cidadania civil - que coincide com a capacidade de estipular contratos e de vincular-se, mediante consenso próprio, a empenhos e prestações nos confrontos com outros sujeitos, e, por fim a cidadania social - a qual estabelece um conjunto de expectativas que 0 cidadão espera do Estado, para obter a garantia de uma certa qualidade de vida.

Seguindo essa evolução histórica da conquista de direitos, eles se firmaram com o advento das revoluções burguesas ocorridas na França e nos Estados Unidos da América no século XVIII. Com elas, estabelecem-se as Cartas Constitucionais, as quais se opõem ao processo dominante da sociedade feudal e às normas arbitrárias do regime monárquico ditatorial, anunciando uma relação jurídica denominada de Estado de Direito. Assim, o Estado de Direito surge para estabelecer direitos iguais a todos os homens, ainda que perante a Lei, e apontar para a redução da desigualdade a que os homens estavam submetidos. Com a emergência da sociedade capitalista, tem-se a ascensão da burguesia em luta contra o feudalismo, retomando-se pouco a pouco o exercício da cidadania, como parte da sociedade vivendo novamente em núcleos urbanos.

Partindo dessa constatação, Bobbio (1992) aborda o conceito de cidadania moderna, tratando o Estado democrático de direito como base para uma cidadania mais abrangente. Para Bobbio (1992) 0 
indivíduo, como membro do Estado, encontra-se no exercício dos direitos políticos que lhe confere participar da vida política.

Hannah Arendt (2000) aborda o conceito de cidadania a luz da concepção entre esfera pública e privada, utilizando-se como base central a "Polis Grega". Polis era o espaço público de referência na Grécia, considerada como local público que definia o ser político, onde tudo era decidido mediante palavras e persuasão. Para Arendt (2000) com o surgimento das cidades-estados, o homem assume uma segunda vida. Além da esfera privada (vida familiar) o homem dialoga acerca de muitos assuntos relevantes de interesse comum, alcançando assim, a esfera pública. De acordo com Arendt (2000) quando o homem alcança a vida pública é dono de si, ou seja, tem liberdade. Assim, o conceito de cidadania de Hannah Arendt, requer o acesso ao espaço público para que ocorra a igualdade política e vai além da participação política por meio do voto.

Os trabalhos teóricos desenvolvidos sobre o conceito de cidadania mais recentemente, apontam no caminho da dualidade das noções de cidadania. Para Vieira $(1999$, p. 1) "há um renovado interesse pela cidadania nos anos 90. O conceito de cidadania parece integrar noções centrais de filosofia política, como os reclamos da justiça e participação política". Assim, cidadania está vinculada à ideia de direitos individuais e participação do processo político.

No Brasil, a cidadania é um conceito em construção, principalmente, devido à negação dos direitos básicos à maioria da população. Desde o período colonial com a escravidão, passando pela República Velha, as eleições e o voto de cabresto, até mesmo o poder exercido pelos coronéis. Essa herança do coronelismo ainda hoje traz reflexos para as condições atuais de democracia. Nesse aspecto, vale ressaltar a confluência entre o público e privado dos interesses dominantes pelas relações patrimonialistas e de cordialidade. Sobre esta temática - as imbricações entre o direito público e o privado - Bobbio (2018) realiza extensa análise sobre as supostas contradições existentes entre as duas dimensões, ao afirmar que "[...] a dicotomia clássica entre direito privado e direito público reflete a situação de um grupo social no qual já ocorreu a diferenciação entre aquilo que pertence ao grupo enquanto tal, à coletividade, e aquilo que pertence aos membros singulares; [...] (Bobbio, 2018, p. 15).

\subsection{Democracia participativa e a sociedade civil}

O avanço na conquista da cidadania por parte da sociedade civil pressupõe ampla participação nos processos decisórios. Com efeito, o exercício da cidadania nos governos democráticos implica na relação entre a prática democrática e o processo deliberativo. 
Alguns autores discutem as questões norteadas por teorias que fundamentam a democracia participativa, com a inserção da esfera pública no âmbito do debate do processo democrático. Faleiros (2010, p. 292) chama atenção para a questão de que

a cidadania pode ser considerada, ao longo da história, e na teoria aqui exposta, como inclusão das pessoas na esfera pública do direito, ao mesmo tempo como sujeitos participantes da definição dessa esfera pública e como credores do Estado em proteção individual e coletiva. Essa inclusão significa que a sociedade civil se expressa politicamente, e a sociedade política reconhece direitos da sociedade civil.

Nota-se que não somente a instituição de espaços participativos garante a ampliação da argumentação e do poder decisório da sociedade civil, pois formas sóciohistóricas da relação entre Estado e Sociedade Civil podem construir barreiras para a ampliação da esfera pública, como o clientelismo, ou mesmo o conservadorismo (Bobbio, 2018; Chaui, 2007; Santos, 2013). Nesse contexto, quando tais espaços são suprimidos, promove uma redução da esfera pública e da participação social. Do mesmo modo, é imperioso moldar os projetos quando o que está em disputa são os significados (Dagnino, 2004), os quais giram em torno da concepção de sociedade civil, especialmente no que se remete à participação e à cidadania democrática, a qual se apoia na participação do indivíduo no contexto social e nas relações constituídas com o Estado. Neste aspecto, Vieira (1992, p. 73) afirma que a cidadania "constitui um princípio de igualdade, realizada na igualdade jurídica e materializada numa sucessão de direitos. Assim, é relevante 0 papel da participação no conjunto da democracia liberal".

Avritzer (2000), no artigo intitulado "Teoria Democrática e deliberação pública", aborda as definições da Teoria Democrática de duas formas. Por um lado, aponta as reflexões de autores clássicos que privilegiam o aspecto decisório, no interior do processo deliberativo, ao tratar da vontade da maioria. No entanto, essa Teoria Democrática hegemônica, segundo o autor "[...] tem dado lugar a uma concepção alternativa, que utiliza o segundo significado etimológico do conceito de deliberação, qual seja, a ideia de um processo de discussão e avaliação no qual os diferentes aspectos de uma determinada proposta são pesados" (Avritzer, 2000, p. 26).

Nessa perspectiva, tem surgido, desde os anos 70, uma nova proposta no interior da Teoria Democrática contemporânea: trata-se da inserção do elemento argumentativo no interior do processo deliberativo. Corroborando com o pensamento de Avritzer (2000), Faria (2000, p. 47-48) acrescenta que:

Sem abrir mão dos procedimentos próprios da organização do poder dessas sociedades regra da maioria, eleições periódicas e divisão dos poderes - a Teoria Democrática deliberativa afirma que o processo de decisão do governo tem de ser sustentado por meio da deliberação dos indivíduos racionais em fóruns amplos de debate e negociação. Essa deliberação não resulta de um processo agregativo das preferências fixas e individuais mas de um processo de comunicação, em espaços públicos, que antecede a própria formação da vontade dos cidadãos. 
Fazendo uma analogia com o que pontua Faria (2000) e Avritzer (2000), há a passagem da Teoria Democrática baseada em um conceito decisório de deliberação para um conceito argumentativo de deliberação. Assim, a sociedade civil na esfera pública deve, entretanto, ter os direitos iguais de cidadania e por conseguinte, participar efetivamente das decisões tomadas no nível do sistema político. Faria (2000, p. 53) afirma que:

A sociedade civil, base social da esfera pública autônoma, constituída por associações, organizações e movimentos sintonizados com a ressonância dos problemas societários, nas esferas da vida privada, absorve e transmite as questões ali tematizadas de forma amplificada para a esfera pública.

A sociedade civil acaba influenciando a definição de questões que serão discutidas na esfera pública. Vale ressaltar, juntamente com Durigueto (2007, p. 54-55) que "a sociedade civil expressa a articulação dos interesses das classes pela inserção econômica, mas também pelas complexas mediações ideopolíticas e socioinstituicionais". Dessa forma, a participação da sociedade civil articula institucionalmente o processo decisório para se alcançar decisões legítimas. Lubenow (2010, p. 236) assevera que "na linguagem habermasiana, o procedimento da democracia deliberativa constitui o âmago do processo democrático. A esfera pública, por sua vez, é a categoria normativa chave do processo político deliberativo habermasiano". Estas pontes elaboradas entre a democracia deliberativa e a ordem democrática a partir da valorização da esfera pública como espaço autêntico para a discussão, o entendimento e o consenso, são relatadas em vários estudos (Brasil, Carneiro, Anelli \& Longuinho, 2019; Gohn, 2004; Oliveira, Cançado \& Pereira, 2010; Sabione; Ferreira \& Reis, 2018).

Durigueto (2007) se fundamenta na Teoria de Habermas, que deriva dos procedimentos de deliberação e tomada de decisões a partir da institucionalização dos canais de participação para legitimar o processo democrático. Assim, a esfera pública constitui-se a arena das discussões composta por associações formadoras de opinião, como os sindicatos, associações populares e grupos de interesse.

Habermas (1984), ao fundamentar a sua teoria, está preocupado como o modo que a opinião pública participa do processo democrático. Nessa teoria, tem-se um conjunto de pressupostos teórico-normativos que incorporam a participação da sociedade civil na regulação da vida coletiva (Faria, 2000). Habermas (1984) promove o rompimento com o decisionismo e a fundação da teoria argumentativa com a ideia de que a razão estabelece uma relação entre participação e argumentação pública. Para o autor, existe a dimensão argumentativa no interior da relação Estado e sociedade civil para além da vontade geral.

Faz-se importante considerar que nas últimas décadas do século XX no Brasil, ocorreu certo avanço da democratização com a progressiva valorização da democracia participativa. Houve, portanto, 0 aprofundamento das discussões acerca da ideia de participação no campo da gestão urbana. Como exemplo da valorização da democracia participativa no país, tem-se 0 orçamento participativo. 0 orçamento 
participativo é um mecanismo dos governos municipais que submete o destino de parte dos recursos públicos à consulta da população, por meio de audiências públicas, reuniões abertas aos cidadãos para a coleta de propostas.

Assim sendo, a partir da década de 1980, emerge no país, um quadro de mudanças que assume papel importante nas questões de ordem política, integrando a sociedade em um conjunto de medidas adotadas pelo Estado, como aponta Nogueira (2004, p. 118) ocorre o "reconhecimento de que a participação não somente conteria um valor em si, como também seria particularmente relevante no fortalecimento de sustentabilidade às Políticas Públicas e ao próprio desenvolvimento".

A participação expandiu-se no campo da gestão pública. No entender de Nogueira (2004) o novo status adquirido pela participação na gestão pública corresponde não apenas à mudança política e ao espectro teórico-ideológico, mas as exigências da modernidade radicalizada e da globalização capitalista. Dessa forma, o mesmo autor, considerando o mundo da sociedade de classes, do capitalismo e do Estado democrático representativo aponta quatro grandes modalidades de participação: participação assistencialista, participação corporativa, participação eleitoral e participação política (Nogueira, 2004).

A participação assistencialista de natureza filantrópica ou solidária se refere a ações filantrópicas direcionadas aos segmentos mais empobrecidos da população e é caracterizada pelas práticas de auxílio mútuo e mutirão. A participação corporativa diz respeito à defesa de interesses específicos de determinados grupos sociais ou de categorias profissionais, objetivando um propósito particular em que somente os que fazem parte do grupo são beneficiados. Por seu turno, a participação eleitoral não interfere somente na defesa de interesses particulares, mas também diretamente na governabilidade, produzindo efeitos diretos na coletividade. Por fim, a participação política integra e ultrapassa tanto a participação eleitoral quanto a participação corporativa, tendo em vista que é a participação que consolida, protege e dinamiza a cidadania e todos os direitos humanos, tendo como protagonistas centrais, os cidadãos (Nogueira, 2004).

Nesse contexto, a combinação dessas modalidades de participação trouxe desafios ao instituto da representação e, aos poucos, a democracia representativa liberal foi desvelando os seus limites e dificuldades em conviver com sociedades sempre mais pluralistas, complexas e fragmentadas. Desse modo, a democracia representativa liberal entrará em crise devido à complexificação e à adversidade dos partidos políticos, à questão das escolhas eleitorais e aos efeitos políticos alcançados pela mídia.

Além disso, a recuperação da ideia de democracia participativa, a partir do surgimento do decisionismo popular por intermédio dos cidadãos, dos movimentos sociais e das associações, contribuíram para o crescimento da democracia participativa. Por outro lado, e não menos importante, é que sob o cenário da normalização da desigualdade (SNYDER, 2019), deve-se atuar para que os direitos sociais sejam restabelecidos e que os desdobramentos do autoritarismo não deem combustível para a ampliação do 
desequilíbrio social (Piketty, 2020). A Constituição de 1988, foi fundamental na implementação de espaços de ampliação da cidadania e na participação da sociedade civil. Dessa forma, a concepção de cidadania é fortalecida com as práticas políticas que consolidaram as mudanças institucionais incluídas na Constituição de 1988. No bojo dessas mudanças, pode-se citar as políticas públicas de acesso a saúde por meio do SUS (Sistema único de Saúde) e a reivindicação de Movimentos Sociais Urbanos para inserção na Carta Constituinte de artigos que trata da Política Urbana.

\subsection{A inserção da participação popular na política urbana}

No contexto da inserção da participação popular como processo decisório popular dos cidadãos, nas décadas de 1970 e 1980, emergem no país movimentos populares contrários à ditadura e à situação econômica do Brasil. Nos anos de 1980, o país atravessou uma crise econômica desencadeada, principalmente, pela elevada dívida externa acumulada em décadas anteriores.

Surgem, no bojo da política, novas práticas que incorporaram a ideologia neoliberal, enfraquecendo 0 planejamento estatal. Dessa forma, as Políticas Públicas são enfraquecidas para corroborar com maior ênfase à iniciativa privada. Sob este cenário, Villaça (1999, p. 231) afirma que:

Os anos de 1970 marcam uma nova etapa na consciência popular urbana no Brasil, com o fortalecimento dos movimentos populares. Nos anos de 1980, especialmente com a mobilização estimulada pelas possibilidades - embora limitadas - de influenciar na elaboração da nova Constituição do país, esses movimentos cresceram em organização, adesões e atuação.

Essas novas práticas políticas, juntamente com as mudanças que delinearam a década de 1980, levantaram discussões nos movimentos sociais acerca das injustiças sociais. Nesse sentido, no final da década de 1980, consolida-se um Movimento Nacional pela Reforma Urbana (MNRU) que reuniu movimentos sociais, entidades sindicais, entidades acadêmicas e de pesquisa, ONGs (Organizações NãoGovernamentais), integrantes da Igreja Católica, etc. Este movimento ganha força em todo o país, mobilizando diversos movimentos populares, contando, adicionalmente, com um cenário de redemocratização com o processo de elaboração da nova Constituição Federal, que admitia a ampla participação popular através da apresentação de emendas de iniciativas populares. Nesta linhagem conceitual, Teixeira (1997, p. 181) assenta que "de fato, o que parece ter-se erodido foi um tipo de participação direta e de movimento popular, caracterizadamente urbano, de bairros, reivindicativo e de protesto de massa".

O MNRU conseguiu reunir diferentes setores da sociedade em prol da questão da Política Urbana. Para tanto, as questões prioritárias foram organizadas em uma proposta de Emenda Constitucional (EC) de iniciativa popular. De maneira geral, pela primeira vez na história do Brasil, as cidades passaram a contar 
com artigos específicos da Constituição Federal referente à Política Urbana no tocante a função social da cidade e à função social da propriedade urbana.

O processo de abertura política do país, por meio da democratização participativa, provenientes da CF/88, passam a representar as formas mais apropriadas de participação popular na formulação, na análise, na implantação, na gestão e no acompanhamento de Políticas Públicas. Neste particular, Secchi, Coelho \& Pires (2019, p. 139) afirmam que:

Os atores relevantes em um processo de política pública são aqueles que têm capacidade de influenciar, direta ou indiretamente, o conteúdo e os resultados da política pública. São os atores que conseguem sensibilizar a opinião pública sobre problemas de relevância coletiva. São os atores que têm influência na decisão do que entra ou não na agenda (grifos originais).

Entretanto, a Constituição Federal (CF), promulgada em 05 de outubro de 1988, atendeu algumas reivindicações do MNRU. Do projeto de emenda de iniciativa popular da Reforma Urbana foram aprovados alguns itens que estão presentes nos artigos 181 e 182 que trata da Política Urbana. Ficou evidenciado que vários movimentos sociais e instituições influenciaram de forma significativa na inserção das questões sociais na legislação urbana do país, significando que o controle social e a participação atuaram efetivamente no processo de alinhamento entre as demandas sociais e uma realidade até então observada.

Convém assinalar que a partir da década de 1990, o planejamento urbano é amparado na Nova Constituição com a inserção dos capítulos inerentes à Política Urbana. O MNRU ganha certa notoriedade no contexto nacional, tanto por parte do governo como da sociedade. Um importante marco da reforma urbana quanto ao processo de participação da sociedade na elaboração e execução do planejamento urbano ocorre com a publicação da Lei № 10.2571 de 10 de julho de 2001, conhecido como Estatuto da Cidade (EC), o qual destaca os instrumentos de planejamento urbano como o plano diretor e a gestão democrática da cidade. A este respeito, Silva (2003, p. 29-30) enfatiza que:

A sociedade incorporou a discussão em torno do Estatuto, no bojo da luta pela Reforma Urbana reacendendo o desejo coletivo do direito à cidade, expresso em práticas políticas e ações mobilizadoras na busca insistente pelo direito de morar e aí viver dignamente, fazendo da cidade um território mais justo e democrático. Só após 11 anos de discussões e negociações o Congresso aprovou o Estatuto da Cidade, lei que fixa parâmetros para aplicação do capítulo da Política Urbana da Constituição Federal de 1988, definindo princípios e objetivos, diretrizes de ação e instrumentos de gestão urbana a serem utilizados, principalmente pelo poder público municipal.

Depois de dez anos tramitando no Congresso Nacional por várias comissões, as quais atrasavam as votações devido às divergências entre os empresários do setor imobiliário e os setores ligados aos movimentos sociais urbanos, finalmente foi aprovado o Estatuto da Cidade que regulamenta os artigos $182 \mathrm{e}$ 183 da CF/1988, que trata da Política Urbana. 
O Estatuto da Cidade reafirma a importância da utilização dos instrumentos de planejamento voltados para a promoção do direito à cidade e uma gestão democrática que visa a garantir o acesso à terra urbana, à moradia digna, ao transporte, aos serviços públicos, ao trabalho e ao lazer. Dessa forma, o Estatuto, fortalece a gestão democrática e a função social da cidade e da propriedade, ou seja, regula 0 uso da propriedade urbana em favor da coletividade e do bem-estar dos citadinos.

A aprovação do Estatuto da Cidade contribuiu para a regulação do uso e da ocupação do solo urbano, tanto quanto para fortalecer a gestão democrática do espaço urbano. Os instrumentos do Estatuto aplicados por meio do Plano Diretor Participativo, elaborado através de um processo participativo, constitui-se um meio eficaz para que o planejamento e a gestão obtenham resultados significativos. Conforme define Braga (2001, p. 98), "o Plano Diretor é um instrumento eminentemente político, cujo objetivo precípuo deverá ser o de dar transparência e democratizar a Política Urbana, ou seja, o plano diretor deve ser, antes de tudo, um instrumento de gestão democrática da cidade".

$\mathrm{Na}$ perspectiva do caráter participativo dos planos diretores - constituindo-se uma conquista dos movimentos populares - 0 processo de participação da sociedade civil nas decisões acerca da Política Urbana dos municípios ganhou destaque com a exigência da inserção popular na elaboração do plano. Os planos diretores, exigidos pelo EC aborda uma nova concepção de planejamento. É nesse contexto que se introduz um caráter mais participativo, com uma maior preocupação social, motivado pela mobilização popular dos anos 80 .

No Brasil, a gestão praticada, em grande parte das cidades, tem-se caracterizado pela centralização das decisões em torno dos gestores e técnicos do aparelho administrativo dos municípios comprometidos em atender os interesses do capital e dos grupos políticos em detrimento de um desenvolvimento urbano mais justo. Com a redemocratização do país, a Constituição Federal de 1988 e o Estatuto da Cidade, inauguraram uma nova fase na gestão democrática e participativa. Com efeito, a participação nas decisões ganha destaque e os citadinos começam a exercer seus direitos de cidadão.

O Ministério das Cidades, criado em 2003, passou a fortalecer o planejamento urbano nos municípios através de ações desenvolvidas pela Secretaria Nacional de Programas Urbanos (SNPU). Sob esse aspecto, a SNPU criou o Programa de Fortalecimento da Gestão Urbana com objetivo de contribuir com os municípios na implementação dos instrumentos do EC, elaboração e revisão dos Planos Diretores. A despeito do acompanhamento do processo de elaboração e implementação dos planos diretores, o Ministério das Cidades, por meio da Secretaria Nacional de Programas Urbanos implantou, em 2007, o projeto "Rede de Avaliação e Capacitação para a Implementação dos Planos Diretores Participativos".

O projeto teve como principal objetivo constituir uma rede de avaliação e monitoramento de planos diretores a partir da contribuição de atores sociais e de pesquisadores, visando a subsidiar a avaliação do 
conteúdo dos planos diretores. Para tanto, o Ministério das Cidades designou como instituição responsável pela execução e coordenação do projeto a Universidade Federal do Rio de Janeiro (UFRJ), por meio do Instituto de Pesquisa e Planejamento Urbano e Regional (IPPUR).

Desde então, o IPPUR constituiu uma equipe de profissionais para desenvolver uma pesquisa sobre a avaliação dos planos diretores municipais selecionados por cada estado. Como desdobramento científico, os resultados dos estudos feitos nos planos diretores municipais foram publicados no livro "Os Planos Diretores Municipais Pós-Estatuto da Cidade: Balanço crítico e perspectivas" (Santos Junior \& Montandon, 2011).

A publicação está dividida em três partes. A primeira parte faz uma síntese das análises e apresenta desafios e recomendações para o fortalecimento do planejamento urbano nos municípios. A segunda parte é dividida nas avaliações temáticas, como o acesso à terra urbanizada, habitação, saneamento ambiental, transporte e mobilidade e sistema de gestão e participação democrática. A última parte discute as experiências de capacitação e avaliação dos Planos Diretores Participativos. Pode-se destacar como resultados alcançados da publicação a ampliação do debate sobre a importância dos Planos Diretores como ferramentas de democratização e a reflexão sobre os instrumentos contidos no Estatuto da Cidade, principalmente na perspectiva da garantia da função social da cidade.

Assim, algumas experiências inovadoras anteriores à aprovação do Estatuto da Cidade, implantadas nas administrações municipais, com relação à participação popular, têm contribuído para a inserção da sociedade nas discussões do espaço urbano. Sob o paradigma da participação, Souza (2002, p. 321) afirma que "sob um ângulo autonomista, os instrumentos de planejamento, por mais relevantes e criativos que sejam, só adquirem verdadeira importância ao terem sua operacionalização (regulamentação) e sua implementação influenciadas e monitoradas pelos cidadãos".

As experiências de participação popular na gestão urbana no Brasil têm sido pouco expressivas, todavia. No entanto, alguns governos municipais, desenvolveram iniciativas no âmbito da gestão democrática participativa. No período correspondente aos anos de 1989 a 2001, tendências inovadoras delinearam a gestão das cidades de Fortaleza, Recife, Santos e Porto Alegre. Essas experiências de gestão trazem uma nova concepção de coordenação do orçamento público municipal, com a institucionalização de um processo participativo da sociedade civil na forma de gerir as políticas públicas locais. Os referidos modelos de gestões bem sucedidas foram relatados por um estudo desenvolvido pelo Centro Josué de Castro de Estudos e Pesquisas, conforme afirma Soares \& Gondim (1998, p. 61), "A análise é baseada principalmente nos relatórios dos estudos de caso elaborados a partir de Fortaleza, Recife, Santos e Porto Alegre, no âmbito da pesquisa Desafios da gestão local democrática, coordenada pelo Centro Josué de Castro de Estudos e Pesquisas". 
Os municípios pesquisados apresentam características diferenciadas do ponto de vista político, administrativo e socioeconômico. Um aspecto muito positivo dessas administrações, segundo Soares e Gondim (1998), foi a introdução do orçamento participativo e os conceitos de parceria e de desenvolvimento econômico local. Em síntese, as quatro gestões pesquisadas obtiveram resultados significativos na política de planejamento participativo.

Por conseguinte, podem-se destacar algumas características, tais como: a visão estratégica da atuação do governo em termos políticos, administrativos e econômicos; substituição do clientelismo por estratégias mais modernas de legitimação; reconhecimento de uma imagem mais favorável da cidade e uma nova concepção de democracia, que enfatiza a participação popular e as parcerias do poder público com diferentes agentes sociais (Soares \& Gondim, 1998).

$\mathrm{Na}$ discussão do processo participativo, corroboram também para o êxito da gestão democrática participativa, a participação da população nas audiências públicas e na inserção nos conselhos. A audiência pública constitui um importante instrumento da democracia participativa (Gurgel, 2020) na busca do diálogo entre os órgãos públicos e os atores sociais, com objetivo de encontrar alternativas para a solução de problemas que afligem a sociedade. Nos eventos de audiência pública, os órgãos públicos estão abertos para ouvir a população e os agentes sociais que estão envolvidos na discussão de questões do interesse público.

No entanto, atualmente, temos observado uma conjuntura desfavorável para a mobilização dos canais participativos no país. Nesse contexto, pode-se inserir a Política Urbana que sofreu considerável retrocesso com o desmonte das conquistas socais alcançadas ao longo das últimas décadas. Por conseguinte, nota-se uma certa inflexão conservadora do atual governo, impactando a gestão democrática das cidades e 0 enfraquecendo as políticas públicas urbanas. Corroborando com o exposto, a extinção do Ministério das Cidades significa um grande retrocesso ou estagnação da Política Urbana no Brasil. Assim, os avanços obtidos pela Constituição Federal de 1988 - e quase vinte anos de vigência do Estatuto da Cidade com relevância para a implantação dos Planos Diretores e suas revisões - estão comprometidos por uma política de desmonte e fechamento dos canais de participação, como os Conselhos da Cidade.

Adicionalmente, para agudizar o problema da participação democrática no que diz respeito às Políticas Públicas, dentre as quais a Política Urbana representa uma vertente relevante no processo de transformação da perspectiva espacial, convém mencionar o Decreto n. 9.759/2019 (BRASIL, 2019), emitido pela Presidência da República, o qual extinguiu os conselhos e os colegiados de representação da Administração Pública. Tentar compreender as motivações que induziram o Poder Executivo a adotar a revogação dos conselhos e dos colegiados - considerando que tais instâncias, denominadas Instituições Participativas, vinham sendo reformuladas, readequadas e requalificadas, desde a $\mathrm{CF} / 88$ - torna-se um grande desafio para os pesquisadores do campo. 


\section{MÉTODO}

O presente estudo possui uma abordagem qualitativa (Yin, 2016), de natureza descritiva, cujo desenvolvimento está apoiado no objetivo do trabalho e busca a descrição imparcial de uma realidade específica (Minayo, 2014), porque o olhar centra-se na descrição de um fenômeno, sem a interferência direta do pesquisador. Para Cooper \& Schindler (2011, p. 164), um estudo qualitativo "[...] inclui um conjunto de técnicas interpretativas que procuram descrever, decodificar, traduzir e, de outra forma, apreender 0 significado, e não a frequência, de certos fenômenos ocorrendo de forma mais ou menos natural no mundo social".

O estudo se apoia em consistente pesquisa bibliográfica e documental (Decretos, Leis, Plano Diretor, etc.), com o fito de contextualizar, apreender os sentidos e compreender as limitações acerca da teoria relacionada ao objeto de estudo. Vale-se, do mesmo modo, de aspectos históricos para melhor embasar e verificar a influência das dinâmicas pretéritas, as quais influenciam os encaminhamentos da Política Urbana atual (Políticas Públicas), a partir das lentes históricas que permeiam o processo democrático-participativo do sujeito social, à luz da Constituição Federal de 1988 (CF/88). Ao adotar as técnicas metodológicoprocedimentais que suportaram a pesquisa, intencionou-se desvelar o conteúdo dos movimentos históricos sobre a temática (cidadania, democracia, participação ativa do sujeito social, engajamento dos arranjos sociais), contextualizando-os sob uma perspectiva contemporânea, sempre observando a realidade que envolve a formação da consciência ético-política no que concerne à Política Urbana.

Assim, por meio das informações levantadas, busca-se revelar as características e os conhecimentos acerca do objeto do estudo, propiciando uma análise crítica e conceitual sobre a relação causa-efeito, a qual se fixa no entorno da Política Urbana no Brasil, tendo como pano de fundo as possibilidades de participação do tecido societário nas decisões que representam o atendimento às demandas sociais, contribuindo para a garantia dos destinos coletivos.

\section{CONCLUSÕES}

No Brasil, emergiram as Leis, as quais contemplavam os direitos sociais. Algum tempo depois, surge a preocupação com os direitos políticos. Observando este escalonamento histórico, viu-se que o significado de cidadania restou bastante prejudicado. A cidadania, embora seja definida com base na atribuição do direito de votar e ser votado, exige a participação individual nas decisões coletivas e na reivindicação e no reconhecimento de direitos sociais. 
A cidadania, então, deixa de vincular-se exclusivamente à participação política, para alcançar, acima de tudo, o comportamento do indivíduo na sociedade e a busca do bem-estar social. As profundas mudanças que ocorreram na década de 1980, decorrentes das reivindicações dos movimentos pela Reforma Urbana, culminaram na inserção de artigos na nova Constituição Federal que trata da Política Urbana. Entretanto, é imperioso destacar a atuação do MNRU, que influenciou consideravelmente no fortalecimento da participação popular no que se refere ao planejamento urbano.

É importante considerar que havendo a inserção popular no processo decisório da Política Urbana Municipal, o planejamento para implantação de um sistema de gestão participativa, suscitando formas de participação da sociedade civil, garantirá a promoção da transparência na Política Urbana e do exercício da cidadania pelos citadinos. Nestes termos, o accountability se torna etapa relevante no contexto da adoção das Políticas Públicas.

Assim, com a aprovação do Estatuto da Cidade, e a obrigatoriedade da elaboração dos planos diretores participativos, reafirma-se a importância da utilização de instrumentos urbanos que promovam uma gestão democrática do espaço urbano. A grande questão posta é se os instrumentos urbanísticos do EC, os planos diretores participativos e as recomendações do Ministério das Cidades serão colocados em prática pelas administrações municipais.

De maneira geral, os planos diretores raramente trataram da regulamentação dos principais instrumentos do Estatuto da Cidade, e, por conseguinte, até o presente, não se consolidou no âmbito nacional, uma Política Urbana que promova o real direito à cidade e o cumprimento da função social da propriedade na formação de uma cidade democrática.

Por fim, a formulação e implementação de Políticas Públicas na Gestão Urbana deve ter como pressuposto os mecanismos de participação da sociedade civil nas decisões da Política Urbana. A democracia participativa é fundamento básico para a consolidação da cidadania. No entanto, na realidade brasileira há um longo caminho para garantir a participação da população no processo decisório da Política Urbana. Além disso, pode-se constatar a inexpressiva participação da sociedade civil no âmbito da formulação de Políticas Públicas voltadas para as cidades, o que requer do sujeito social uma postura mais incisiva e participativa no tocante à busca da garantia dos direitos sociais. 


\section{REFERÊNCIAS}

Arendt, H. (2000). Entre o passado e o futuro. 5. ed. São Paulo: Perspectiva.

Avritzer, J. (2000). Teoria Democrática e deliberação pública. São Paulo: CEDEC.

Bobbio, N. (2018). Estado, governo e sociedade: fragmentos de um dicionário político. (21a. ed.). Rio de Janeiro/São Paulo: Paz e Terra.

Bobbio, N. (1992). O futuro da democracia. (15a. ed.) Rio de Janeiro/São Paulo: Paz e Terra.

Braga, R. (2001). Política Urbana e Gestão Ambiental: considerações sobre o Plano Diretor e zoneamento urbano. In P. F. Carvalho, \& R. Braga (Eds.)

Perspectivas de Gestão Ambiental em cidades médias (p. 95 a 109). Rio Claro: LPM - UNESP.

Brasil. Constituição (1988). Constituição da República Federativa do Brasil. Brasília, DF: Senado 1988.

Brasil, Ministério das Cidades (2004). Plano Diretor Participativo. Guia para elaboração pelos municípios e cidadãos. Brasília: CONFEA e Ministério das Cidades.

Brasil. (2019). Presidência da República. Decreto $n^{0}$ 9.759 de 11 de abril de 2019. Extingue e estabelece diretrizes, regras e limitações para colegiados da administração pública federal. Brasília, DF: Subchefia de Assuntos Jurídicos/PR.

Brasil, F. P. D., Carneiro, R., Anelli, F. R. \& Longuinho, L. P. (2019). Participação e deliberação na gestão pública: desafios e potencialidades Dos Fóruns Regionais de Governo. Revista de Políticas Públicas, 23(2), 863-881. DOI: http://dx.doi.org/10.18764/21782865.v23n2p863-881.

Carvalho, J. M. de. (2008). Cidadania no Brasil: o longo caminho (11a ed.). Rio de Janeiro: Civilização Brasileira.

Chauí, M. (2007) Cultura e democracia: o discurso competente e outras falas. (12a ed.) São Paulo: Cortez.

Cooper, D. R. \& Schindler, P. S. (2011). Métodos de pesquisa em Administração. (10a. ed.). Porto Alegre: Bookman.

Dagnino, E. (2004). Construção Democrática, Neoliberalismo e Participação: os dilemas da confluência perversa. Política e Sociedade: revista de sociologia política, 3(5), 139-164. DOI: https: //doi.org/10.5007/\%25x.

Durigueto, M. L. (2007). Sociedade Civil e Democracia: um debate necessário. São Paulo-SP: Cortez Editora.
Faleiros, V. P. (2010). Cidadania e política. In D. E. C. Luiz (Ed.), Sociedade civil e democracia: expressões contemporâneas (p. 275-302). São Paulo: Veras editora.

Faria, C. F. (2000). Democracia deliberativa:

Habermas, Cohen e Bohman. Lua Nova, (50), 47-68.

DOI: https://doi.org/10.1590/S0102-

64452000000200004

Gohn, M. G. (2004). Empoderamento e participação da comunidade em políticas sociais. Revista Saúde e Sociedade, 13(2), 20-31. DOI: https://doi.org/10.1590/S0104-12902004000200003.

Gurgel, C. (2020). Democracia participativa brasileira e a participação social nas cidades: a experiência do orçamento como instrumento de controle externo: da legitimidade para uma cidadania com responsabilidade - confiança e participação. Caderno de Direitos e Políticas Públicas, 2(2), 21-49.

Habermas, J. (1984). Mudança estrutural da esfera pública. Rio de Janeiro: Tempo Brasileiro.

Lubenow, J. A. (2010). Esfera Pública e Democracia Deliberativa em Habermas - Modelo teórico e discursos críticos. Kriterion, 51(121), 227-258. DOI: https://doi.org./10.1590/50100512X2010000100012.

Marshall, T. H. (1967). Cidadania e classe social. In T. H. Marshall (Ed.), Cidadania, classe social e status. (p. 57-114). Rio de Janeiro: Zahar.

Minayo, M. C. S. (2014). O desafio do conhecimento: pesquisa qualitativa em saúde. São Paulo: Hucitec

Morbini, F. K., \& Melo, J. A.M. H. (2020). A educação como elemento essencial à participação popular $\mathrm{e}$ construção da cidadania. Humanidades \& Inovação, 7 (19), 103-113. DOI: https://orcid.org/0000-0001-69522067

Nogueira, M. A. (2004). Um Estado para a Sociedade Civil: temas éticos e políticos da gestão democrática. (2a ed.) São Paulo: Cortez.

Oliveira, V. A. R., Cançado, A. C., \& Pereira, J. R. (2010). Gestão social e esfera pública: aproximações teórico-conceituais. Cadernos EBAPE, BR, 8 (4), 613626. DOI: https://doi.org/10.1590/5167939512010000400004

Piketty, T. (2020). Capital e ideologia. Rio de Janeiro: Intrínseca.

Sabione, M., Ferreira, M. A. M., \& Reis, A. O. (2018). Racionalidades na motivação para a participação 
cidadã no controle social: uma experiência local brasileira. Cadernos EBAPE.BR, 16 (1), 81-100. DOI: https://doi.org/10.1590/1679-395155420

Santos, B. S. (2013). Pela mão de Alice: O Social e o Político na Pós-Modernidade. (14a ed.). São Paulo: Cortez.

Santos Junior, O. A \& Montandon, D. T. (2011). Os Planos Diretores Municipais Pós-Estatuto da Cidade: balanço crítico e perspectivas. (1a ed., Vol. 1). Rio de Janeiro: Letra Capital, Observatório das Metrópoles, IPPUR/UFRJ.

Secchi, L., Coelho, F. S., \& Pires, V. (2019). Políticas Públicas: conceitos, casos práticos, questões de concurso. (3a ed.). São Paulo: Cengage.

Silva, J. B. (2003). Estatuto da Cidade versus Estatuto da Cidade - Eis a questão. In A. Lemos \& G. Inês \& A. F. Carlos (Eds.), Dilemas urbanos: novas abordagens sobre a cidade. São Paulo: Contexto.

Silveira, J. I. (2017). Assistência social em risco: conservadorismo e luta social por direitos. Serviço Social \& Sociedade, São Paulo, (130), 487-506. DOI: https://doi.org/10.1590/0101-6628.120

Snyder, T. (2019). Na contramão da liberdade: a guinada autoritária nas democracias contemporâneas. São Paulo: Companhia das Letras.

Soares, J. A., \& Gondim, L. (1998). Novos modelos de gestão: lições que vêm do poder local. In J. A. Soares \& S. Caccia-Bava (Eds.), Os desafios da gestão municipal democrática. São Paulo: Cortez.

Souza, M. L. de. (2002). Mudar a Cidade: uma introdução Crítica ao Planejamento e à Gestão Urbanos. (1a ed.). Rio de Janeiro: Bertrand Brasil.

Teixeira, E. (1997). As Dimensões da Participação Cidadã. Caderno CRH, 26(27), 179-209. DOI: http://dx.doi.org/10.9771/ccrh.v10i26.18669

Tocqueville, A. (2019). Da democracia na América. Tradução de Pablo Costa e Hugo Medeiros. Campinas, SP: VIDE Editorial.

Vieira, L. (1999). Cidadania global e estado nacional. (v. 42, n. 03). Rio de Janeiro: Dados.

Vieira, E. (1992). Democracia e Política Social. São Paulo: Cortez; São Paulo: Autores Associados.
Villaça, F. (1999). Uma contribuição para a história do planejamento urbano no Brasil. In C. Deák \& S. R. Schiffer (Eds.) O processo de urbanização no Brasil (p. 169-243). São Paulo: EdUSP.

Yin, R. K. (2016). Pesquisa qualitativa: do início ao fim. Porto Alegre: Penso. 